\title{
Short-Term Outcome of Combined Corticosteriod and Local Anaestetic Therapy with Home-Based Exercıse Programme in Painful Shoulder Conditions
}

\author{
S Toker ${ }^{1}$, V Kılınçoğlu ${ }^{1}$, A Toker ${ }^{2}$, E Gulcan ${ }^{3 \star}$, E Ertürer ${ }^{4}$, L \\ Sahin $^{5}$
}

${ }^{1}$ Department of Orthopaedics and Traumatology, Dumlupinar University School of Medicine, ${ }^{2}$ Department of Clinical Biochemistry, Yoncali Physical Therapy and Hidrotherapy Hospital ${ }^{3}$ Department of Internal Medicine, Dumlupinar University School of Medicine, ${ }^{4}$ Department of Orthopaedics and Traumatology, Sisli Etfal Research and Training Hospital, ${ }^{5}$ Department of Anesthesiology and Reanimation, Dumlupinar University School of Medicine, 43000 Kutahya, Turkey.

\begin{abstract}
Purpose: The aim of this study was to evaluate the efficacy of combined local corticosteroid and anaestethic therapy with home exercise programme in the treatment of painful shoulder conditions.

Methods: $40 \mathrm{mg}$ Depomedro ${ }^{\circledR}$ (methylprednisolone acetate) $+120 \mathrm{mg}$ Citanest $^{\Theta}$ (procaine hydrochloride) were parenterally administered into the subacromial region of 28 patients (17 female, mean age: 48 years; 11 male, mean age: 52 years) from a group of patients who have been suffering from shoulder pain for a period of at least two months and had received no benefit from previous treatments. Simultaneously, they were placed on a home-based shoulder exercise programme. The patients were seen two months later and questioned about their conditions. The data were evaluated together with clinical findings based on the range of motion (ROM) of the shoulder.

Results: Twenty of 28 patients (71.42\%) reported complete relief from pain, 5 patients or $17.85 \%$ stated that they had only partial relief of pain, and 3 patients $(10.71 \%)$ said that the level of pain remained essentially the same. Nineteen of 28 patients (67.85\%) had good to excellent ROM while $3(10.71 \%)$ still manifested poor ROM.

Conclusion: Local corticosteroid plus local anaestethic therapy together with home exercise programme was found to be an economic, effective and safe short-term treatment in the management of painful shoulder conditions arising from certain disorders.
\end{abstract}

Key Words: Painful shoulder, Local corticosteroid, Local anaesthetic, Home exercise programe, Range of motion. 


\section{INTRODUCTION}

Painful shoulder is the second most common musculosceletal disorder. The most common factors leading to painful shoulder are trauma, spasticity following stroke, osteoarthritis and overuse ${ }^{1}$. Often, the initial treatment consists of physical therapy, rest and oral anti-inflammatory drugs ${ }^{2}$. Some other conditions causing painful shoulder are subacromial bursitis, degeneration of acromioclavicular joint, tendonitis, adhesive capsulitis, impingement syndrome and rotator cuff tears. Lack of appropriate examination and inadequate routine polyclinic examinations often lead to a delay in accurate diagnosis and appropriate treatment of patients suffering from shoulder pain ${ }^{3}$.

Patients often gain limited benefit from oral anti-inflamatory drugs and limitations in shoulder joint motions and pain usually persists. As a result, atrophy due to immobility of the joint may occur and a vicious circle of muscle strength loss, limitation in function and more intense pain may ensue 4 .

Local corticosteroid injections administered into the intra-articular regions or peri-articular structures such as bursas intended to relieve rheumatological symptoms. The procedure is cheap and well tolerated unless it is applied repeatedly in the same region ${ }^{5}$. The efficacy of local cotticosteroid injection has been evaluated in numerous clinical studies ${ }^{6-7}$.

In this study, we sought to evaluate the efficacy of combined parenteral administration of a local corticosteroid and a local anaestethic, when combined with a home exercise programme, in the treatment of painful shoulder conditions.

\section{PATIENTS AND METHODS}

The data reported in this paper are retrospective. Thirty one patients (19 female, age: $48 \pm 19$ years, 12 ; male mean age:52 \pm 16 years) suffering from shoulder pain and various limitations in shoulder joint motions for at least two month (1-6 months), without a trauma history and another disease such as diabetes, stroke, cardiac disease, rheumatological disease and previous shoulder surgery were taken into study. Patients were called to score the pain from zero to ten before and after the treatment $(0$ : no pain; 1-3: negligible; 4-7: moderate; 8-10: excessive) as indicated in Table 2 . The range of shoulder joint motion was assesed by physical examination before and after treatment (Table 3). Twelve of 31 patients had great limitation in range of motion (ROM) of the shoulder (i.e., adhesive capsulitis or minimal ROM) while 16 patients had moderate limitation (i.e., up to 90 degrees anterior and lateral elevation). Three patients had no limitation in ROM of shoulder joint (i.e., full ROM).

Routine physical examination, anteroposterior and lateral transthoracic $\mathrm{x}$-ray radiography, haemogram, erythrocyte sedimentation rate (ESR), c-reactive protein (CRP), rheumatoid factor (RF) blood tests and magnetic resonance imaging (MRI) were performed for all patients.

According to data obtained by these examinations, ten of 31 patients ( 5 female, 5 male) were determined to have frozen shoulder(adhesive capsulitis, AC) while six patients (3 female, 3 male) had tendonitis and tendonosis (T-T); seven patients (5 female, 2 male) had subacromial bursitis (SAB), and eight patients (5 female, 3 male) had rototor cuff tear (RCT) as shown in Table 1.

In eleven (11) patients, acromioclavicular joint degeneration (ACJD) was detected together with other pathologies. Impingement symptoms (IS) were found in four of the eleven patients having rototor cuff tear, tendonitis and tendonosis.

The same clinician administered the drugs parenterally into posterior subacromial region all of the patients. The drugs administered were $40 \quad \mathrm{mg} \quad$ Depomedrol $^{\circledR}$, (methylprednisolone acetate) and $120 \mathrm{mg}$ Citanest $^{\circledR}$ (procaine hydrochloride). All patients were instructed to carry out Codman's shoulder exercises ${ }^{8}$. and administered the same dose of the above anti-inflammatory drugs were given. Patients were seen for clinical examination after two month and the findings were recorded. 
Table 1: Distribution of disorders

\begin{tabular}{llccccl}
\hline \multicolumn{2}{c}{ AC } & T-T & SAB & RCT & ACJD & IS \\
\hline $10(5$ & FM,5 & $6(3 \mathrm{FM}, 3 \mathrm{M})$ & $7(5 \mathrm{FM}, 2 \mathrm{M})$ & $8(5 \mathrm{FM}, 3 \mathrm{M})$ & 13 & 5 \\
$\mathrm{M})$ & & & & &
\end{tabular}

Abbreviations: $A C$ : adhesive capsulitis, $T$-T: tendonitis and tendonosis, SAB: subacromial bursitis, RCT: rototor cuff tear, ACJD: acromioclavicular joint degeneration, IS: Impingement symptoms, FM: female, M: Male

Table 2: Patients' definition of pain (compared with pain before treatment) after the first month

\begin{tabular}{llll}
\hline No pain (0) & Negligible pain(1-3) & Moderate pain (4-7) & Excessive pain(8-10) \\
\hline $\begin{array}{l}\text { Before } \\
\text { treatment: } 0\end{array}$ & $\begin{array}{l}\text { Before treatment: } 4 \\
(12.9 \%)\end{array}$ & $\begin{array}{l}\text { Before treatment: 13 } \\
(41.9 \%)\end{array}$ & $\begin{array}{l}\text { Before treatment: } 14 \\
(45.1 \%)\end{array}$ \\
$\begin{array}{l}\text { After } \\
\text { treatment: } 21\end{array}$ & $\begin{array}{l}\text { After treatment: } 4 \\
(12.9 \%)\end{array}$ & $\begin{array}{l}\text { After treatment: } 3 \\
(9.6 \%)\end{array}$ & After treatment: $3(9.6 \%)$ \\
\hline
\end{tabular}

Table 3: Range of Motion (ROM) before and after treatment.

\begin{tabular}{|c|c|c|}
\hline $\begin{array}{l}\text { Excessive Limitation } \\
\text { (eg., AC) }\end{array}$ & $\begin{array}{l}\text { Moderate limitation (Up to } 90 \\
\text { degrees anterior and lateral } \\
\text { elevation) }\end{array}$ & No Limitation(Full ROM) \\
\hline $\begin{array}{l}\text { Before treatment: } 12 \\
(38.7 \%)\end{array}$ & Before treatment: $16(51.6 \%)$ & Before treatment: 3 (9.6\%) \\
\hline $\begin{array}{l}\text { After treatment: } 2 \\
(6.4 \%)\end{array}$ & After treatment: 12 (38.7\%) & \\
\hline
\end{tabular}

Statistical analysis was performed by SPSS 14 programme with Wilcoxon Signed Ranks Test, and $p$ values lower than 0.005 were regarded to be statistically significant.

\section{RESULTS}

When patients were asked to compare the pain they had before and after treatment by scoring between zero and ten, twenty-one of 31 patients $(67.7 \%)$ had complete relief of pain while four patients $(12.9 \%)$ had a satisfactory decrease in pain (negligible pain, i.e., 1-3 on the pain scale). Three patients each $(9.6 \%)$ had moderate pain after treatment (4-7 pain scale) and experienced no difference in degree of pain (8-10 points), respectively. The mean pain score was 6.7742 before treatment but this fell to 1.3548 after the treatment plus exercise programme. The results were found to be statistically significant $(p<0.001)$ (Table 2$)$

During physical examination, it was observed that seventeen of 31 patients $(54.8 \%)$ had nearly full range of motion (ROM) of the shoulder while 12 patients $(38.7 \%)$ had moderate ROM and 2 patients (6.4\%) excessive limitation in ROM (see Table 3). The mean anterior and lateral elevation ROM was 63.87 degrees before treatment which increased to 86.45 degrees after treatment. These results were also found to be statistically significant $(p<0.001)$. 


\section{DISCUSSION}

The painful shoulder is the second most common musculosceletal disorder ${ }^{9}$. Subacromial corticosteroid and local anaestethic injection is commonly used in painful shoulder cases. In the literature, corticosteroid injection is recommended for chronic painful cases in which other treatment procedures were ineffective after at least two months ${ }^{10-12}$. Corticosteroids inhibit the synthesis of prostaglandins and also reduce the activity of collagenase and other enzymes. However, the basic mechanism for positive effects in osteoarthritis is still unclear. In a study by Saxne et $\mathrm{al}^{13}$, it was shown that corticosteroids reduced the production of interleukin-1, tumour necrosis factor alpha, and proteases which all cause an erosion of cartilage.

It is known that glenohumeral and acromioclavicular joint osteoarthritis are not the only responsible pathologies in painful shoulder cases. It is reasonable to expect that corticosteroids reduce inflammation by similar mechanisms as they do for pain in other diseases such tendonitis, impingement, bursitis and adhesive capsulitis. It has been stated that there is disagreement among the clinicians about the most appropriate local anaestethic dosage in painful shoulder conditions $^{6}$. Chae et $\mathrm{al}^{14}$ stated that significant recovery in clinical symptoms could be obtained by subacromial corticosteroid injection but further studies should be undertaken in order to distinguish its effect from spontaneous recovery. In our study, we did not enrol patients who had painful shoulder after a stroke. In a previous study, Yu et al $^{15}$ reported $91 \%$ satisfactory results in patients with subacromial pathologies (impingement, tendonitis and bursitis) after the first month and $88 \%$ at the end of the first year. However, the same investigators also stated that subacromial corticosteroid and local anaestethic injection were an effective treatment modality in pain relief and recovery in ROM. In our own study, we obtained nearly $80 \%$ satisfactory outcome at the end of the first month. The difference between these two sets of results may be due to the other pathologies which some of the patients in our study also suffered from which included adhesive capsulitis, rototor cuff tear and acromioclavicular joint degeneration.

The efficacy of intra-articular steroid injection for rototor cuff tear and adhesive capsulitis has been proved in recent studies ${ }^{16}$. Arrol et al, in a meta-analysis study, found that subacromial corticosteroid injection was effective in pain release for about nine months and the treatment was more effective than non-steroid anti-inflammatory drugs However, the authors further stated that higher corticosteroid doses might be more effective ${ }^{2}$.

Esenyel et al used the anterolateral region as the site of steroid injection and reported $87.5 \%$ success in finding the right target for the drug. They stated that this would be higher if the posterior region had been used $^{17}$. In our study, we administered drugs to the posterior region and obtained $80 \%$ clinical success reduction in pain reduction although we did not evaluate amount of the drugs that reached target in the region. Armstrong et al stated that systemic absorption of steroids injected locally depended on drug dose and solubility, and that $40 \mathrm{mg}$ of methylprednisolone acetate could cause temporary adrenal supression and lower cortisole levels for up to 7-19 days $^{2}$. Neustadt pointed out that it might be possible to minimise the systemic effects of the drugs by a reduction in patient's physical activity after injection ${ }^{18}$. We did not observe any complication due to systemic absorption of the drugs administered; however we believe that the patient should be advised to rest the joint for a while after injection.

\section{CONCLUSION}

We come to the conclusion that combined parenteral administration of a local corticosteroid (methylprednisolone acetate) and a local anaesthetic (procaine hydrochloride) together with a home-based physical therapy (Codman's exercises) can reduce the pain and increase $R O M$ significantly on a short term in patients having 
shoulder pain. This treatment modality is effective, easy to perform, affordable and shows minimal complications.

\section{REFERENCES}

1. Armstrong RD, English J, Gibson T, Chakraborty J, Marks $V$. Serum methylprednisolone levels following intra-articular injections of methylprednisolone acetate. Ann Rheum Dis 1981; 40: 571-574.

2. Arroll B, Goodyear-Smith F. Corticosteroid injections for painful shoulder: a metaanalysis. Br J Gen Pract. 2005;55 (512): 224-8

3. Lorei MP, Hershman EB. Peripheral nerve injuries in athletes. Treatment and prevention. Sports Med. 1993 Aug;16(2):130-47

4. Pucheu $B$, Duhautois $B$. Surgical treatment of shoulder instability. A retrospective study on 76 cases (1993-2007). Vet Comp Orthop Traumatol. 2008;21(4):368-74

5. Kang MN, Rizio L, Prybicien M, Middlemas DA, Blacksin MF. The accuracy of subacromial corticosteroid injections: a comparison of multiple methods. J Shoulder Elbow Surg. 2008 Jan-Feb;17(1 Suppl):61S-66S

6. Skedros JG, Hunt KJ, Pitts TC. Variations in corticosteroid/anesthetic injections for painful shoulder conditions: comparisons among orthopaedic surgeons, rheumatologists, and physical medicine and primary-care physicians. BMC Musculoskelet Disord. 2007 Jul 6;8:63.

7. Yu CM, Chen CH, Liu HT, Dai MH, Wang IC, Wang $K C$. Subacromial injections of corticosteroids and xylocaine for painful subacromial impingement syndrome. Chang Gung Med J. 2006 SepOct;29(5):474-9

8. Akgün $K$, Birtane $M$, Akarirmak $U$. Is local subacromial corticosteroid injection beneficial in subacromial impingement syndrome? Clin Rheumatol. 2004 Dec;23(6):496-500
9. Lisiński P, Grabarczyk G. Aspects of physiotherapy in treatment of shoulder joint pain. Chir Narzadow Ruchu Ortop Pol. 2005; 70(4): 295-9.

10. Speed CA. Fortnightly review: Corticosteroid injections in tendon lesions. BMJ 2001; 323: 382-6.

11. Mantone JK, Burkhead WZ Jr, Noonan J Jr. Nonoperative treatment of rotator cuff tears. Orthop Clin North Am 2000; 31: 295-311.

12. Green $S$, Buchbinder $R$, Glazier $R$, Forbes $A$. Systematic review of randomised controlled trials of interventions for painful shoulder: selection criteria, outcome assessment, and efficacy. BMJ 1998; 316: 354-60.

13. Saxne T, Heinegard D, Wollheim FA. Therapeutic effects on cartilage metabolism in arthritis as measured by release of proteoglycan structures into the synovial fluid. Ann Rheum Dis 1986; 45: 491-497.

14. Chae J, Wolf-Johnson T, Govil H. Subacromial corticosteroid injection for poststroke shoulder pain: a retrospective chart review. Arch Phys Med Rehabil. 2007; 88 (12). 1690-3.

15. Yu CM, Chen CH, Liu HT, Dai MH, Wang IC, Wang KC. Subacromial injections of corticosteroids and xylocaine for painful subacromial impingement syndrome. Chang Gung Med J. 2006; 29(5): 474-9.

16. Moskowitz RW, Blaine TA. An overview of treatment options for persistent shoulder pain. Am J Orthop. 2005; 34 (12 Suppl): 10-5.

17. Esenyel CZ, Esenyel M, Yeşiltepe R, Ayanoğlu S, Bülbül $M$, Sirvanci $M$, Kara AN. The correlation between the accuracy of steroid injections and subsequent shoulder pain and function in subacromial impingement syndrome. Acta Orthop Traumatol Turc 2003; 37(1): 41-45.

18. Neustadt $D H$. Intra-articular injections for osteoarthritis of the knee. Cleve Clin J Med. 2006 ;73(10): 897-8, 901-4, 906-11. 